\title{
Professor
}

\section{Francisco Escobar del Rey}

Prof. Francisco Escobar del Rey passed away in Madrid on December 16, 2015 at the age of 92 years. He was born in Villaviciosa de Cordoba, Spain, of which he was a 'favorite son'. In the 1950s he graduated from the Medical School of Granada. He completed his doctoral thesis on the administration of iodized salt in the iodine-deficient region of Alpujarras under the mentorship of Prof. Ortiz de Landazuri. From then on, his scientific career has been inseparable from that of his wife, Prof. Gabriela Morreale. They worked for several years at the University of Leiden with Prof. Andreas Querido. Upon their return to Spain in 1958, they founded the Thyroid Study Unit at the High Research Council. In 1974 they moved to the Autonomous University of Madrid and were co-founders of the Instituto de Investigaciones Biomédicas. Prof. Escobar participated in numerous studies on thyroid gland physiology and on thyroid hormone metabolism. He and Gabriela made fundamental contributions to thyroidology, including the physiological importance of $\mathrm{T}_{4}$ to $\mathrm{T}_{3}$ conversion in peripheral tissues, the transfer of thyroid hormones across the placenta, and the importance of maternal hormones in the developing fetus. They performed

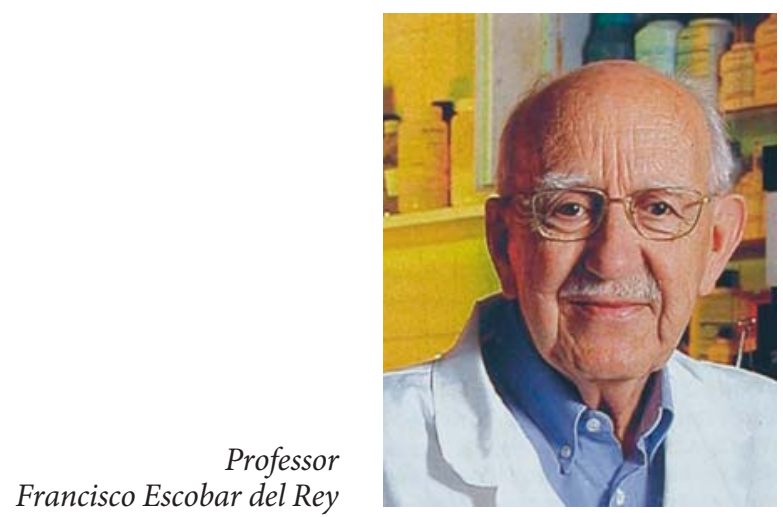

studies in iodine-deficient regions of Spain and promoted salt iodization. They also established the program for the screening of congenital hypothyroidism in newborns. Prof. Escobar remained active until 2007 when he retired at the age of 84 . He is survived by his spouse, Prof. Gabriela Morreale de Escobar, his son Dr. Hector EscobarMorreale, and his two grandchildren, Inés and Francisco.

Juan Bernal 